\title{
Fixed points for multivalued contractions with respect to a Pompeiu type metric
}

Iulia Coroian

Department of Land Measurements and Exact Sciences, University Of Agricultural Sciences and Veterinary Medicine, 3-5 Manastur St., 400372 Cluj-Napoca, Romania.

Communicated by A. Petrusel

\begin{abstract}
The purpose of this paper is to present a fixed point theory for multivalued $\mathrm{H}^{+}$-contractions from the following perspectives: existence/uniqueness of the fixed and strict fixed points, data dependence of the fixed point set, sequence of multivalued operators and fixed points, Ulam-Hyers stability of a multivalued fixed point equation, well-posedness of the fixed point problem, limit shadowing property for a multivalued operator, set-to-set operatorial equations and fractal operator theory. (C)2017 All rights reserved.
\end{abstract}

Keywords: $\mathrm{H}^{+}$-type multivalued mapping, Lipschitz equivalent metric, multivalued operator, contraction. 2010 MSC: 47H10, 54H25.

\section{Introduction}

Let $(X, d)$ be a metric space and $\mathcal{P}(X)$ be the set of all subsets of $X$. We denote

$$
\begin{aligned}
P(X) & :=\{Y \in \mathcal{P}(X) \mid Y \neq \emptyset\}, \\
P_{c l}(X) & :=\{Y \in \mathcal{P}(X) \mid Y \text { is closed }\}, \\
P_{b, c l}(X) & :=\{Y \in \mathcal{P}(X) \mid Y \text { is bounded and closed }\}, \\
P_{c p}(X) & :=\{Y \in \mathcal{P}(X) \mid Y \text { is compact }\} .
\end{aligned}
$$

By $B(x, r)$ and respectively $\tilde{B}(x, r)$ we will denote the open and respectively the closed ball centered at $x \in X$ with radius $r>0$.

The following (generalized) functionals are used in the main sections of the paper.

1. The gap functional generated by $\mathrm{d}$ :

$$
D_{d}: P(X) \times P(X) \rightarrow \mathbb{R}_{+} \cup\{\infty\}, \quad D_{d}(A, B)=\inf \{d(a, b) \mid a \in A, b \in B\} .
$$

2. The diameter generalized functional:

$$
\delta: P(X) \times P(X) \rightarrow \mathbb{R}_{+} \cup\{\infty\}, \quad \delta(A, B)=\sup \{d(a, b) \mid a \in A, b \in B\} .
$$


3. The excess generalized functional:

$$
\rho_{\mathrm{d}}: \mathrm{P}(\mathrm{X}) \times \mathrm{P}(\mathrm{X}) \rightarrow \mathbb{R}_{+} \cup\{\infty\}, \quad \rho_{\mathrm{d}}(\mathrm{A}, \mathrm{B})=\sup \left\{\mathrm{D}_{\mathrm{d}}(\mathrm{a}, \mathrm{B}) \mid \mathrm{a} \in \mathrm{A}\right\} .
$$

4. The Hausdorff-Pompeiu generalized functional:

$$
H_{d}: P(X) \times P(X) \rightarrow \mathbb{R}_{+} \cup\{\infty\}, \quad H_{d}(A, B)=\max \left\{\rho_{d}(A, B), \rho_{d}(B, A)\right\} .
$$

5. The Pompeiu generalized functional:

$$
\mathrm{H}_{d}^{+}: \mathrm{P}(X) \times \mathrm{P}(X) \rightarrow \mathbb{R}_{+} \cup\{\infty\}, \quad \mathrm{H}_{d}^{+}(\mathrm{A}, \mathrm{B}):=\frac{1}{2}\left\{\rho_{\mathrm{d}}(\mathrm{A}, \mathrm{B})+\rho_{\mathrm{d}}(\mathrm{B}, \mathrm{A})\right\} .
$$

We will avoid the subscript $d$ when we work with just one metric $d$ on $X$.

Let $(X, d)$ be a metric space. If $T: X \rightarrow P(X)$ is a multivalued operator, then $x \in X$ is called fixed point for $T$ if and only if $x \in T(x)$. We denote by $F_{T}$ the fixed point set of $T$ and by $(S F)_{T}$ the set of all strict fixed points of $T$, i.e., elements $x \in X$ such that $T(x)=\{x\}$.

Concerning the Pompeiu functional $\mathrm{H}^{+}$defined above, we have several properties.

Lemma 1.1 ([13]). The following conclusions take place:

(a) $\mathrm{H}^{+}$is a metric on $\mathrm{P}_{\mathrm{b}, \mathrm{cl}}(\mathrm{X})$;

(b) $\mathrm{H}^{+}$is a generalized metric (in the sense that it can take also infinite values) on $\mathrm{P}_{\mathrm{cl}}(\mathrm{X})$.

Using the Pompeiu type functional $\mathrm{H}^{+}$, the following notion was introduced in [13], see also [12].

Definition $1.2([13])$. Let $(X, d)$ be a metric space. A multivalued mapping $T: X \rightarrow P_{b, c l}(X)$ is called $\mathrm{H}^{+}$-contraction with constant $\alpha$, if

1. there exists a fixed real number $\alpha, 0<\alpha<1$ such that for every $x, y \in X$

$$
\mathrm{H}^{+}(\mathrm{T}(\mathrm{x}), \mathrm{T}(\mathrm{y})) \leqslant \alpha \mathrm{d}(\mathrm{x}, \mathrm{y}) ;
$$

2. for every $x \in X, y \in T(x)$ and for every $\epsilon>0$ there exists $z$ in $T(y)$ such that

$$
d(y, z) \leqslant H^{+}(T(x), T(y))+\varepsilon .
$$

Remark 1.3. Let $(\mathrm{X}, \mathrm{d})$ be a metric space. A multivalued mapping $\mathrm{T}: \mathrm{X} \rightarrow \mathrm{P}_{\mathrm{cl}}(\mathrm{X})$ is called $\left(\mathrm{H}^{+}, \alpha\right)$-Lipschitz if $\alpha>0$ and

$$
\mathrm{H}^{+}(\mathrm{T}(\mathrm{x}), \mathrm{T}(\mathrm{y})) \leqslant \alpha \mathrm{d}(\mathrm{x}, \mathrm{y}), \quad \forall x, \mathrm{y} \in \mathrm{X} .
$$

If $0<\alpha<1$, then $\mathrm{T}$ is called a multivalued $\left(\mathrm{H}^{+}, \alpha\right)$-contraction.

The purpose of this paper is to study different properties of the Pompeiu functional $\mathrm{H}^{+}$and of the multivalued operators satisfying a Lipschitz condition with respect to $\mathrm{H}^{+}$. The connections with some continuity notions for multivalued operators are also given. The second purpose of this paper is to extend the results given in [13], by presenting several properties of the fixed point set of multivalued $\mathrm{H}^{+}$-contractions. Several other fixed point results and applications of it will be also given.

\section{Properties of the Pompeiu type functional}

Concerning the functional $\mathrm{H}^{+}$defined above, we have some nice properties.

Lemma 2.1 ([13]). We have the following relations:

$$
\frac{1}{2} H(A, B) \leqslant H^{+}(A, B) \leqslant H(A, B),
$$

(i.e., $\mathrm{H}$ and $\mathrm{H}^{+}$are strong equivalent metrics).

Proposition $2.2([13])$. Let $(\mathrm{X},\|\cdot\|)$ be a normed linear space. For any $\lambda$ (real or complex), $\mathrm{A}, \mathrm{B} \in \mathrm{P}_{\mathrm{b}, \mathrm{cl}}(\mathrm{X})$

1. $H^{+}(\lambda A, \lambda B)=|\lambda| H^{+}(A, B)$;

2. $H^{+}(A+a, B+a)=H^{+}(A, B)$. 
Theorem 2.3 ([13]). If $\mathrm{a}, \mathrm{b} \in \mathrm{X}$ and $\mathrm{A}, \mathrm{B} \in \mathrm{P}_{\mathrm{b}, \mathrm{cl}}(\mathrm{X})$, then the following relations hold:

1. $d(a, b)=H^{+}(\{a\},\{b\})$;

2. $A \subset \bar{S}\left(B, r_{1}\right), B \subset \bar{S}\left(A, r_{2}\right) \Rightarrow H^{+}(A, B) \leqslant r$ where $r=\frac{r_{1}+r_{2}}{2}$.

Theorem $2.4([13])$. If the metric space $(\mathrm{X}, \mathrm{d})$ is complete, then $\left(\mathrm{P}_{\mathrm{cp}}(\mathrm{X}), \mathrm{H}^{+}\right),\left(\mathrm{P}_{\mathrm{b}, \mathrm{cl}}(\mathrm{X}), \mathrm{H}^{+}\right)$and $\left(\mathrm{P}_{\mathrm{cl}}(\mathrm{X}), \mathrm{H}^{+}\right)$ are complete too.

The following concept was introduced by Nadler jr. as follows.

Definition 2.5. Let $(X, d)$ be a metric space. A mapping $T: X \rightarrow P_{c l}(X)$ is called a multivalued $\alpha$ contraction if $\alpha \in(0,1)$ and

$$
H(T(x), T(y)) \leqslant \alpha d(x, y), \quad \forall x, y \in X .
$$

Notice that any multivalued $\alpha$-contraction is an $\left(\mathrm{H}^{+}, \alpha\right)$-contraction, but the reverse implication does not hold.

We will now introduce a similar concept. For this purpose, we recall now the concept of (strong) comparison function.

Definition 2.6. A mapping $\varphi: \mathbb{R}_{+} \rightarrow \mathbb{R}_{+}$is said to be a comparison function if it is increasing and $\varphi^{\mathrm{k}}(\mathrm{t}) \rightarrow 0$, as $\mathrm{k} \rightarrow+\infty$.

As a consequence, we also have $\varphi(t)<t$, for each $t>0, \varphi(0)=0$ and $\varphi$ is continuous in 0 .

Definition 2.7. A mapping $\varphi: \mathbb{R}_{+} \rightarrow \mathbb{R}_{+}$is said to be a strong comparison function if it is a comparison function and $\sum_{k=0}^{\infty} \varphi^{k}(t)<\infty$, for any $t>0$.

With respect to the Pompeiu type functional $\mathrm{H}^{+}$, we define the following concept.

Definition 2.8. Let $(X, d)$ be a metric space. Then, the multivalued operator $T: X \rightarrow P_{b, c l}(X)$ is called a $\varphi$-contraction w.r.t. $\mathrm{H}^{+}$, if

1. $\varphi: \mathbb{R}_{+} \rightarrow \mathbb{R}_{+}$is a strong comparison function;

2. for all $x, y \in X$, we have that

$$
\mathrm{H}^{+}(\mathrm{T}(\mathrm{x}), \mathrm{T}(\mathrm{y})) \leqslant \varphi(\mathrm{d}(\mathrm{x}, \mathrm{y})) .
$$

In particular, if $\varphi: \mathbb{R}_{+} \rightarrow \mathbb{R}_{+}$is defined by $\varphi(t):=k t$ (for some $k \in[0,1[$ ), then $\varphi$ is a strong comparison function and the multivalued operator $\mathrm{T}$ is an $\left(\mathrm{H}^{+}, \mathrm{k}\right)$-contraction.

We recall now some useful concepts in the theory of multivalued operators.

Definition 2.9 (see, for example, $[1,14])$. Let $(X, d)$ be a metric space and $T: X \rightarrow P_{b, c l}(X)$. Then, $T$ is called upper semi-continuous (briefly u.s.c.) in $x \in X$, if for any open subset $U$ of $X$ with $F(x) \subset U$, there exists $\eta>0$ such that $T(B(x ; \eta)) \subset U$. T is u.s.c. on $X$ if it is u.s.c. in each $x \in X$.

Definition $2.10([1,14])$. Let $(X, d)$ be a metric space and $T: X \rightarrow P_{b, c l}(X)$. Then $T$ is called lower semicontinuous (briefly l.s.c.) in $x \in X$, if for all $\left(x_{n}\right)_{n \in \mathbb{N}^{*}} \subset X$ such that $\lim _{n \rightarrow \infty} x_{n}=x$ and for all $y \in T(x)$, there exists a sequence $\left(y_{n}\right)_{n \in \mathbb{N}^{*}} \subset X$ such that $y_{n} \in T\left(x_{n}\right)$, for all $n \in \mathbb{N}^{*}$ and $\lim _{n \rightarrow \infty} y_{n}=y$. $T$ is 1.s.c. on $X$ if it is 1.s.c. in each $x \in X$.

Definition $2.11([1,14])$. Let $(X, d)$ be a metric space. $T: X \rightarrow P_{b, c l}(x)$ is called H-upper semi-continuous in $x_{0} \in X$ (H-u.s.c.) respectively $\mathrm{H}$-lower semi-continuous (H-l.s.c.), if for each sequence $\left(x_{n}\right)_{n \in \mathbb{N}} \subset X$ such that

$$
\lim _{n \rightarrow \infty} x_{n}=x_{0}
$$

we have

$$
\lim _{n \rightarrow \infty} \rho\left(T\left(x_{n}\right), T\left(x_{0}\right)\right)=0 \text {, respectively } \lim _{n \rightarrow \infty} \rho\left(T\left(x_{0}\right), T\left(x_{n}\right)\right)=0 \text {. }
$$


It is well-known that if $T$ is u.s.c. in $x \in X$, then $T$ is $H$-u.s.c. in $x \in X$, while if $T$ is $H$-l.s.c. in $x \in X$ implies that $T$ is l.s.c. in $x \in X$.

Definition $2.12([1,14])$. Let $(X, d)$ be a metric space and $T: X \rightarrow P(X)$. Then $T$ is said to be with closed graph, if for each $x \in X$ and for all $\left(x_{n}\right)_{n \in \mathbb{N}^{*}} \subset X$ such that

$$
\lim _{n \rightarrow \infty} x_{n}=x \text {, }
$$

and for all $\left(y_{n}\right)_{n \in \mathbb{N}^{*}} \subset X$ with $y_{n} \in T\left(x_{n}\right)$, for all $n \in \mathbb{N}^{*}$ and

$$
\lim _{n \rightarrow \infty} y_{n}=y,
$$

we have $y \in T(x)$.

Some properties of a multivalued $\left(\mathrm{H}^{+}, \alpha\right)$-Lipschitz operators are given now.

Theorem 2.13. Let $(\mathrm{X}, \mathrm{d})$ be a metric space and $\mathrm{T}: \mathrm{X} \rightarrow \mathrm{P}_{\mathrm{b}, \mathrm{cl}}(\mathrm{X})$ be $\left(\mathrm{H}^{+}, \alpha\right)$-Lipschitz. Then

1. Thas closed graph in $\mathrm{X} \times \mathrm{X}$;

2. $\mathrm{T}$ is $\mathrm{H}-$ l.s.c. on $\mathrm{X}$;

3. $\mathrm{T}$ is $\mathrm{H}-$ u.s.c. on $\mathrm{X}$;

4. If, additionally $\mathrm{T}$ has compact values, then $\mathrm{T}$ is l.s.c.

Proof.

(1) Let $\left(x_{n}, y_{n}\right) \subset X \times X$ such that $\left(x_{n}, y_{n}\right) \stackrel{d}{\rightarrow}(x, y)$, when $n \rightarrow \infty$ and $y_{n} \in T\left(x_{n}\right)$, for all $n \in \mathbb{N}$. It follows that

$$
\begin{aligned}
D(y, T(x)) & \leqslant d\left(y, y_{n}\right)+D\left(y_{n}, T(x)\right) \\
& \leqslant d\left(y, y_{n}\right)+H\left(T\left(x_{n}\right), T(x)\right) \\
& \leqslant d\left(y, y_{n}\right)+2 H^{+}\left(T\left(x_{n}\right), T(x)\right) \\
& \leqslant d\left(y_{1} y_{n}\right)+2 k d\left(x_{n}, x\right), \quad n \in \mathbb{N} .
\end{aligned}
$$

Let us consider $n \rightarrow \infty$ and we obtain

$$
\mathrm{D}(\mathrm{y}, \mathrm{T}(\mathrm{x})) \leqslant 0 \Rightarrow \mathrm{y} \in \overline{\mathrm{T}(\mathrm{x})}=\mathrm{T}(\mathrm{x}) .
$$

(2) Let $x \in X$ such that $x_{n} \rightarrow x$. We have

$$
\begin{aligned}
\rho\left(T(x), T\left(x_{n}\right)\right) & \leqslant H\left(T(x), T\left(x_{n}\right)\right) \\
& \leqslant 2 \cdot H^{+}\left(T(x), T\left(x_{n}\right)\right) \\
& \leqslant 2 k \cdot d\left(x, x_{n}\right) \rightarrow 0 .
\end{aligned}
$$

In conclusion, $\mathrm{T}$ is $\mathrm{H}-$-l.s.c. on $\mathrm{X}$.

(3) Using the relation

$$
\begin{aligned}
\rho\left(T\left(x_{n}\right), T(x)\right) & \leqslant H\left(T\left(x_{n}\right), T(x)\right) \\
& \leqslant 2 \cdot H^{+}\left(T\left(x_{n}\right), T(x)\right) \\
& \leqslant 2 k \cdot d\left(x, x_{n}\right) \rightarrow 0
\end{aligned}
$$

we obtain that $\mathrm{T}$ is $\mathrm{H}$-u.s.c. on $\mathrm{X}$.

(4) The conclusion follows by the fact that any H-l.s.c. multivalued operator with compact values is l.s.c. (see [11]).

Lemma 2.14. Let $(X, d)$ be a metric space and $\mathrm{T}: \mathrm{X} \rightarrow \mathrm{P}_{\mathrm{cp}}(\mathrm{X})$ such that

$$
H^{+}(T(x), T(y))<d(x, y), \quad \forall x, y \in X, \quad x \neq y .
$$

Then $\mathrm{T}$ is u.s.c. on $\mathrm{X}$. 
Proof. Let $Z \subset Y$ be a closed set. We will prove that $T^{-}(Z)$ is closed in $X$. Let $x \in \overline{T^{-}(Z)} \backslash T^{-}(Z)$ and $\left(x_{n}\right)_{n \in \mathbb{N}} \subset X$ such that $x_{n} \rightarrow x$, when $n \rightarrow \infty, x_{n} \neq x$, for all $n \in \mathbb{N}$ and $x_{n} \in T^{-}(Z)$, for all $n \in \mathbb{N}$. It follows $T\left(x_{n}\right) \cap H \neq \emptyset$, for all $n \in \mathbb{N}$. Let $\left(y_{n}\right)_{n \in \mathbb{N}} \in T\left(x_{n}\right) \cap Z, n \in \mathbb{N}$. Then

$$
D\left(y_{n}, T(x)\right) \leqslant H_{d}\left(T\left(x_{n}\right), T(x)\right) \leqslant 2 H^{+}\left(T\left(x_{n}\right), T(x)\right)<2 d\left(x_{n}, x\right) .
$$

If $n \rightarrow \infty$ we get that

But

$$
\lim _{n \rightarrow \infty} \mathrm{D}\left(\mathrm{y}_{n}, \mathrm{~T}(\mathrm{x})\right)=0
$$

$$
\left.D\left(y_{n}, T(x)\right)=\inf _{y \in T} d\left(y_{n}, y\right)=d\left(y_{n}, x_{n}^{\prime}\right), \quad \text { (using the compactness of the set } T(x)\right) \text {. }
$$

When $n \rightarrow \infty$ we have $d\left(y_{n}, x_{n}^{\prime}\right) \rightarrow 0$. Because $\left(x_{n}^{\prime}\right)_{n \in \mathbb{N}} \subset T(x)$, we obtain that there exists a subsequence $\left(x_{n_{k}}^{\prime}\right)_{k \in \mathbb{N}}$ which converges to an element $\bar{x} \in T(x)$. Then

$$
d\left(y_{n_{k}}, \bar{x}\right) \leqslant d\left(y_{n_{k}}, x_{n_{k}}^{\prime}\right)+d\left(x_{n_{k}}^{\prime}, \bar{x}\right) \text { when } k \rightarrow \infty .
$$

Hence, $y_{n_{k}}^{\prime} \rightarrow \bar{x} \in T(x), n \rightarrow \infty$.

Because $\left(y_{n_{k}}^{\prime}\right)_{k \in \mathbb{N}} \subset Z$ and $Z$ is closed, we obtain that $\bar{x} \in Z$. So $T(x) \cap Z \neq \emptyset$, which implies $x \in T^{-}(Z)$, a contradiction. In conclusion, $\overline{T^{-}(Z)}=T^{-}(Z)$ and hence $T^{-}(Z)$ is closed in $X$.

\section{MWP operators and multivalued $\alpha$-contractions w.r.t. $\mathrm{H}^{+}$}

The following concepts appeared in [15].

Definition 3.1. Let $(X, d)$ be a metric space. Then, $T: X \rightarrow P(X)$ is called a multivalued weakly Picard operator (briefly MWP operator) if for each $x \in X$ and each $y \in T(x)$ there exists a sequence $\left(x_{n}\right)_{n \in \mathbb{N}}$ in $X$ such that:

1. $x_{0}=x, x_{1}=y$;

2. $x_{n+1} \in T\left(x_{n}\right)$, for all $n \in \mathbb{N}$;

3. the sequence $\left(x_{n}\right)_{n \in \mathbb{N}}$ is convergent and its limit is a fixed point of $T$.

Definition 3.2. Let $(X, d)$ be a metric space and $T: X \rightarrow P(X)$ be an MWP operator. Then we define the multivalued operator $T^{\infty}: \operatorname{Graph}(T) \rightarrow P\left(F_{T}\right)$ by the formula $T^{\infty}(x, y)=\left\{z \in F_{T} \mid\right.$ there exists a sequence of successive approximations of $T$ starting from $(x, y)$ that converges to $z\}$.

Definition 3.3. Let $(X, d)$ be a metric space and $T: X \rightarrow P(X)$ an MWP operator. Then $T$ is said to be a c-multivalued weakly Picard operator (briefly c-MWP operator) if and only if there exists a selection $t^{\infty}$ of $T^{\infty}$ such that

$$
d\left(x, t^{\infty}(x, y)\right) \leqslant c d(x, y), \quad \forall(x, y) \in \operatorname{Graph}(T) .
$$

We recall now the notion of multivalued Picard operator.

Definition 3.4. Let $(X, d)$ be a complete metric space and $T: X \rightarrow P(X)$. By definition, $T$ is called a multivalued Picard operator (briefly MP operator) if and only if

1. $(\mathrm{SF})_{\mathrm{T}}=\mathrm{F}_{\mathrm{T}}=\left\{\mathrm{x}^{*}\right\}$;

2. $\mathrm{T}^{\mathrm{n}}(\mathrm{x}) \stackrel{\mathrm{H}}{\rightarrow}\left\{\mathrm{x}^{*}\right\}$ as $\mathrm{n} \rightarrow \infty$, for each $\mathrm{x} \in \mathrm{X}$.

Recall that, by definition, for $\left(A_{n}\right)_{n \in \mathbb{N}} \in P_{c l}(X)$, we will write $A_{n} \stackrel{H}{\rightarrow} A^{*}$ as $n \rightarrow \infty$ if and only if $\mathrm{H}\left(A_{n}, A^{*}\right) \rightarrow 0$ as $n \rightarrow \infty$. Notice also that

$$
A_{n} \stackrel{H}{\rightarrow} A^{*} \in P_{c l}(X) \text { as } n \rightarrow \infty \text { if and only if } A_{n} \stackrel{H^{+}}{\rightarrow} A^{*} \in P_{c l}(X) \text { as } n \rightarrow \infty \text {. }
$$


The purpose of this section is to study some properties of the fixed point set of $\mathrm{H}^{+}$-contraction with constant $\alpha$ from the MWP operator theory point of view.

We will start by presenting some auxiliary results.

Lemma 3.5 (see, for example, [14]). Let $(X, d)$ be a metric space and $A, B \in P_{c l}(X)$. Suppose that there exists $\eta>0$ such that for each $a \in A$ there exists $b \in B$ such that $d(a, b) \leqslant \eta$ and for each $b \in B$ there exists $a \in A$ such that $\mathrm{d}(\mathrm{a}, \mathrm{b}) \leqslant \eta$. Then $\mathrm{H}(\mathrm{A}, \mathrm{B}) \leqslant \eta$.

Lemma 3.6 ([14]). Let $(X, d)$ be a metric space, $A, B \in P(X)$ and $q>1$. Then, for every $a \in A$ there exists $b \in B$ such that $\mathrm{d}(\mathrm{a}, \mathrm{b}) \leqslant \mathrm{qH}(\mathrm{A}, \mathrm{B})$.

Lemma 3.7 ([11]). Let $(X, d)$ be a metric space and $A, B \in P_{c p}(X)$. Then for every $a \in A$ there exists $b \in B$ such that $d(a, b) \leqslant H(A, B)$.

Lemma 3.8 ([16]). Let $(\mathrm{X}, \mathrm{d})$ be a metric space. If $\mathrm{A}, \mathrm{B} \in \mathrm{P}(\mathrm{X})$ and $\epsilon>0$ then for every $\mathrm{a} \in \mathrm{A}$ there exists $\mathrm{b} \in \mathrm{B}$ such that

$$
d(a, b) \leqslant H(A, B)+\epsilon .
$$

Lemma 3.9. Let $(X, d)$ be a metric space, $\mathrm{A}, \mathrm{B} \in \mathrm{P}_{\mathrm{cl}}(\mathrm{X})$ and $\varepsilon>0$. If $\mathrm{H}^{+}(\mathrm{A}, \mathrm{B})<\varepsilon$, then

1. for all $\mathrm{a} \in \mathrm{A}$ there exists $\mathrm{b} \in \mathrm{B}$ such that $\mathrm{d}(\mathrm{a}, \mathrm{b})<\varepsilon$; or

2. for all $b \in B$ there exists $a \in A$ such that $d(a, b)<\varepsilon$.

Proof. Suppose, by reductio ad absurdum, that

(i) there exists $a_{0} \in A$, for all $b \in B$ such that $d\left(a_{0}, b\right) \geqslant \varepsilon$;

(ii) there exists $b_{0} \in B$, for all $a \in A$ such that $d\left(a, b_{0}\right) \geqslant \varepsilon$.

Then, taking $\inf _{b \in B}$ in (i) and $\inf _{a \in A}$ in (ii), we obtain $D\left(a_{0}, B\right) \geqslant \varepsilon$. Since $\rho(A, B) \geqslant D\left(a_{0}\right.$, $B$ ), we get

$$
\rho(A, B) \geqslant \varepsilon .
$$

On the other hand, we also have $D\left(b_{0}, A\right) \geqslant \varepsilon$. Since $\rho(B, A) \geqslant D\left(b_{0}, A\right)$, we get

$$
\rho(B, A) \geqslant \varepsilon .
$$

Adding the above relations and then dividing by 2 , we obtain $\mathrm{H}^{+}(A, B) \geqslant \varepsilon$, which is a contradiction with $\mathrm{H}^{+}(\mathrm{A}, \mathrm{B})<\varepsilon$.

Lemma 3.10 (Cauchy, see [17]). Let $\left(a_{n}\right)_{n \in \mathbb{N}}$ and $\left(b_{n}\right)_{n \in \mathbb{N}}$ be two sequences of non-negative real numbers, such that

$$
\sum_{k=0}^{+\infty} a_{k}<+\infty, \text { and } \lim _{n \rightarrow+\infty} b_{n}=0 \text {. }
$$

Then,

$$
\lim _{n \rightarrow \infty} \sum_{k=0}^{n} a_{n-k} b_{k}=0 .
$$

Theorem 3.11. Let $(\mathrm{X}, \mathrm{d})$ be a complete metric space and $\mathrm{T}: \mathrm{X} \rightarrow \mathrm{P}_{\mathrm{cl}}(\mathrm{X})$ be a multivalued $\mathrm{H}^{+}$-contraction with constant $\alpha$. Then we have

(i) $\mathrm{F}_{\mathrm{T}} \neq \emptyset$.

(ii) $T$ is a $\frac{1}{1-\alpha}$ MWP operator. 
(iii) Let $\mathrm{S}: \mathrm{X} \rightarrow \mathrm{P}_{\mathrm{cl}}(\mathrm{X})$ be an $\mathrm{H}^{+}$-contraction with constant $\alpha$ and $\eta>0$ such that $\mathrm{H}^{+}(\mathrm{S}(\mathrm{x}), \mathrm{T}(\mathrm{x})) \leqslant \eta$, for each $x \in X$. Then $\mathrm{H}^{+}\left(\mathrm{F}_{\mathrm{S}}, \mathrm{F}_{\mathrm{T}}\right) \leqslant \frac{2 \cdot \eta}{1-\alpha}$.

(iv) Let $\mathrm{T}_{\mathrm{n}}: \mathrm{X} \rightarrow \mathrm{P}_{\mathrm{cl}}(\mathrm{X}), \mathrm{n} \in \mathbb{N}$ be a sequence of multivalued $\mathrm{H}^{+}$-contraction with constant $\alpha$ such that $\mathrm{T}_{\mathrm{n}}(\mathrm{x}) \stackrel{\mathrm{H}^{+}}{\rightarrow} \mathrm{T}(\mathrm{x})$ as $\mathrm{n} \rightarrow \infty$, uniformly with respect to $\mathrm{x} \in \mathrm{X}$. Then, $\mathrm{F}_{\mathrm{T}_{\mathrm{n}}} \stackrel{\mathrm{H}^{+}}{\rightarrow} \mathrm{F}_{\mathrm{T}}$ as $\mathrm{n} \rightarrow \infty$.

If, additionally $\mathrm{T}(\mathrm{x}) \in \mathrm{P}_{\mathrm{cp}}(\mathrm{X})$ for each $\mathrm{x} \in \mathrm{X}$, then we also have

(v) (Ulam-Hyers stability of the inclusion $x \in \mathrm{T}(\mathrm{x})$ ) Let $\epsilon>0$ and $\mathrm{x} \in \mathrm{X}$ be such that $\mathrm{D}(\mathrm{x}, \mathrm{T}(\mathrm{x})) \leqslant \epsilon$. Then there exists $x^{*} \in \mathrm{F}_{\mathrm{T}}$ such that $\mathrm{d}\left(\mathrm{x}, \mathrm{x}^{*}\right) \leqslant \frac{\epsilon}{1-\alpha}$.

(vi) The fractal operator $\hat{\mathrm{T}}: \mathrm{P}_{\mathrm{cp}}(\mathrm{X}) \rightarrow \mathrm{P}_{\mathrm{cp}}(\mathrm{X}), \hat{\mathrm{T}}(\mathrm{Y}):=\bigcup_{x \in \mathrm{Y}} \mathrm{T}(\mathrm{x})$ is a $2 \alpha$-contraction.

(vii) If, additionally, $\alpha \in\left[0, \frac{1}{2}\left[\right.\right.$, then $\mathrm{F}_{\hat{\mathrm{T}}}=\left\{\mathrm{A}_{\mathrm{T}}^{*}\right\}$ and $\mathrm{T}^{\mathrm{n}}(\mathrm{x}) \stackrel{\mathrm{H}^{+}}{\rightarrow} \mathrm{A}_{\mathrm{T}}^{*}$ as $\mathrm{n} \rightarrow \infty$, for each $\mathrm{x} \in \mathrm{X}$. Moreover, $\mathrm{F}_{\mathrm{T}} \subset \mathrm{A}_{\mathrm{T}}^{*}, \mathrm{~F}_{\mathrm{T}}$ is compact and

$$
A_{\mathrm{T}}^{*}=\bigcup_{n \in \mathbb{N}^{*}} \mathrm{~T}^{\mathrm{n}}(\mathrm{x}), \quad \forall x \in \mathrm{F}_{\mathrm{T}} .
$$

Proof.

(i) Let $\epsilon>0$ be given. Let $x_{0} \in X$ be arbitrary. Fix an element $x_{1} \in T\left(x_{0}\right)$. From the definition of $\mathrm{H}^{+}$-contraction with constant $\alpha$ it follows that we can choose $\mathrm{x}_{2} \in \mathrm{T}\left(\mathrm{x}_{1}\right)$ such that

$$
\mathrm{d}\left(\mathrm{x}_{1}, \mathrm{x}_{2}\right) \leqslant \mathrm{H}^{+}\left(\mathrm{T}\left(\mathrm{x}_{0}\right), \mathrm{T}\left(\mathrm{x}_{1}\right)\right)+\epsilon .
$$

In general, if $x_{n}$ is chosen, then we choose $x_{n+1} \in T\left(x_{n}\right)$ such that

$$
d\left(x_{n}, x_{n+1}\right) \leqslant H^{+}\left(T\left(x_{n-1}\right), T\left(x_{n}\right)\right)+\epsilon .
$$

Suppose $H^{+}\left(T\left(x_{n-1}\right), T\left(x_{n}\right)\right)>0$ for each $n \in \mathbb{N}^{*}$ (if not, i.e., if there is $k \in \mathbb{N}^{*}$ such that

$$
\mathrm{H}^{+}\left(\mathrm{T}\left(\mathrm{x}_{\mathrm{k}-1}\right), \mathrm{T}\left(\mathrm{x}_{\mathrm{k}}\right)\right)=0,
$$

then $x_{k} \in T\left(x_{k-1}\right)=T\left(x_{k}\right)$ is a fixed point for $T$ and we are done). Let $1<q<\frac{1}{\alpha}$ and set

$$
\epsilon_{\mathrm{n}}:=(\mathrm{q}-1) \mathrm{H}^{+}\left(\mathrm{T}\left(\mathrm{x}_{\mathrm{n}-1}\right), \mathrm{T}\left(\mathrm{x}_{\mathrm{n}}\right)\right) .
$$

Then, from the above relation it follows that

$$
d\left(x_{n}, x_{n+1}\right) \leqslant q H^{+}\left(T\left(x_{n-1}\right), T\left(x_{n}\right)\right) .
$$

Thus, if we set $\beta:=q \alpha<1$, we have

$$
d\left(x_{n}, x_{n+1}\right) \leqslant q H^{+}\left(T\left(x_{n-1}\right), T\left(x_{n}\right)\right) \leqslant q \alpha d\left(x_{n-1}, x_{n}\right)=\beta d\left(x_{n-1}, x_{n}\right),
$$

for all $n \in \mathbb{N}$. Repeating the same argument $n$-times we get a sequence of successive approximations for $T$ starting from $\left(x_{0}, x_{1}\right) \in \operatorname{Graph}(T)$ such that, for each $n \in \mathbb{N}$, we have

$$
d\left(x_{n}, x_{n+1}\right) \leqslant \beta^{n} d\left(x_{0}, x_{1}\right) .
$$

Then,

$$
d\left(x_{n}, x_{n+p}\right) \leqslant \beta^{n} \frac{1-\beta^{p}}{1-\beta} d\left(x_{0}, x_{1}\right), \quad \forall n \in \mathbb{N}^{*}, p \in \mathbb{N}^{*}
$$

This implies that the sequence $\left(x_{n}\right)_{n \in \mathbb{N}}$ is Cauchy and hence convergent in $(X, d)$ to some $X^{*} \in X$. Notice that, by the contraction condition, we immediately get that Graph $(T)$ is closed in $X \times X$. Hence $x^{*} \in F_{T}$. 
(ii) By (3.1), letting $p \rightarrow \infty$, we get that

$$
d\left(x_{n}, x^{*}\right) \leqslant \beta^{n} \frac{1}{1-\beta} d\left(x_{0}, x_{1}\right), \quad \forall n \in \mathbb{N}^{*} .
$$

For $n=1$ we get

$$
d\left(x_{1}, x^{*}\right) \leqslant \frac{\beta}{1-\beta} d\left(x_{0}, x_{1}\right)
$$

Then

$$
d\left(x_{0}, x^{*}\right) \leqslant d\left(x_{0}, x_{1}\right)+d\left(x_{1}, x^{*}\right) \leqslant \frac{1}{1-\beta} d\left(x_{0}, x_{1}\right)=\frac{1}{1-q \alpha} d\left(x_{0}, x_{1}\right) .
$$

Letting $q \searrow 1$ we get that for each $\left(x_{0}, x_{1}\right) \in \operatorname{Graph}(T)$, there exists $x^{*}:=t^{\infty}\left(x_{0}, x_{1}\right) \in F_{T}$ such that

$$
d\left(x_{0}, t^{\infty}\left(x_{0}, x_{1}\right)\right) \leqslant \frac{1}{1-\alpha} d\left(x_{0}, x_{1}\right)
$$

proving that $\mathrm{T}$ is a $\frac{1}{1-\alpha}$-multivalued weakly Picard operator.

(iii) Let $x_{0} \in S\left(x_{0}\right)$ and $q>1$. Then, by Lemma 3.6, there exists $x_{1} \in T\left(x_{0}\right)$ such that

$$
d\left(x_{0}, x_{1}\right) \leqslant q H\left(S\left(x_{0}\right), T\left(x_{0}\right)\right) \leqslant 2 q H^{+}\left(S\left(x_{0}\right), T\left(x_{0}\right)\right) \leqslant 2 q \eta .
$$

Then, by (ii) and the above relation, we have proved that for each $x_{0} \in F_{S}$ there exists $t^{\infty}\left(x_{0}, x_{1}\right) \in F_{T}$ such that

$$
d\left(x_{0}, t^{\infty}\left(x_{0}, x_{1}\right)\right) \leqslant \frac{1}{1-\alpha} d\left(x_{0}, x_{1}\right) \leqslant \frac{1}{1-\alpha} 2 q \eta .
$$

Now Lemma 3.5 tells us that

$$
\rho\left(F_{S}, F_{T}\right) \leqslant \frac{2 q \eta}{1-\alpha} .
$$

By a similar procedure we can prove that for each $y_{0} \in T\left(y_{0}\right)$ there exists $y_{1} \in S\left(y_{0}\right)$ such that

$$
d\left(y_{0}, y_{1}\right) \leqslant q H\left(T\left(y_{0}\right), S\left(y_{0}\right)\right) \leqslant 2 q H^{+}\left(T\left(y_{0}\right), S\left(y_{0}\right)\right) \leqslant 2 q \eta .
$$

Thus, we have proved that for each $y_{0} \in F_{T}$ there exists $s^{\infty}\left(y_{0}, y_{1}\right) \in F_{S}$ such that

$$
d\left(y_{0}, s^{\infty}\left(y_{0}, y_{1}\right)\right) \leqslant \frac{1}{1-\alpha} 2 q \eta .
$$

Again, Lemma 3.5 gives that

$$
\rho\left(F_{S}, F_{T}\right) \leqslant \frac{2 q \eta}{1-\alpha}
$$

Adding (3.2) and (3.3), and then dividing by 2, we get

$$
\mathrm{H}^{+}\left(\mathrm{F}_{\mathrm{S}}, \mathrm{F}_{\mathrm{T}}\right) \leqslant \frac{2 \mathrm{q \eta}}{1-\alpha}, \quad \forall \mathrm{q}>1
$$

Letting $q \searrow 1$, we get the conclusion.

(iv) Let $\epsilon>0$ be given and choose $N_{\epsilon} \in \mathbb{N}$ such that for $n \geqslant N_{\epsilon}$ we have

$$
\sup _{x \in X} H^{+}\left(T_{n}(x), T(x)\right)<\epsilon, \quad n \geqslant N_{\epsilon} .
$$

Then, from (iii), we have

$$
\mathrm{H}^{+}\left(\mathrm{F}_{\mathrm{T}_{\mathrm{n}}}, \mathrm{F}_{\mathrm{T}}\right)<\frac{2 \epsilon}{1-\alpha} \text {, for all } \mathrm{n} \geqslant \mathrm{N}_{\epsilon}
$$

Thus, $\mathrm{F}_{\mathrm{T}_{\mathrm{n}}} \stackrel{\mathrm{H}^{+}}{\rightarrow} \mathrm{F}_{\mathrm{T}}$ as $\mathrm{n} \rightarrow \infty$. 
(v) Let $\epsilon>0$ and $x \in X$ be such that $D(x, T(x)) \leqslant \epsilon$. Then, since $T(x)$ is compact, there exists $y \in T(x)$ such that $d(x, y) \leqslant \epsilon$. By the proof of (i), we have that

$$
d\left(x, t^{\infty}(x, y)\right) \leqslant \frac{1}{1-\alpha} d(x, y)
$$

Since $x^{*}:=t^{\infty}(x, y) \in F_{T}$, we get the conclusion $d\left(x, x^{*}\right) \leqslant \frac{\epsilon}{1-\alpha}$.

(vi) By the contraction condition with respect to $\mathrm{H}^{+}$, one obtains (see Theorem 2.13) that the operator $\mathrm{T}$ is $H$-u.s.c. Since $T(x)$ is compact, for each $x \in X$, we obtain that $T$ is upper semicontinuous. Thus $T$ is u.s.c.

We will prove now that

$$
H^{+}(T(A), T(B)) \leqslant 2 \alpha H^{+}(A, B) .
$$

For this purpose, let $u \in T(A)$. Then there exists $a \in A$ such that $u \in T(a)$. From Lemma 3.7 there exists $\mathrm{b} \in \mathrm{T}(\mathrm{B})$ such that

$$
d(a, b) \leqslant H_{d}(A, B)
$$

Since

$$
D(u, T(B)) \leqslant D(u, T(b)) \leqslant \rho(T(a), T(b)),
$$

taking $\sup _{\mathfrak{u} \in \mathrm{T}(\mathrm{A})}$, we get

$$
\rho(T(A), T(B)) \leqslant \rho(T(a), T(b)) .
$$

Interchanging the roles of $A$ and $B$, we get

$$
\rho(T(B), T(A)) \leqslant \rho(T(b), T(a)) .
$$

Adding the above relations and then dividing by 2, we get

$$
\mathrm{H}^{+}(\mathrm{T}(\mathrm{A}), \mathrm{T}(\mathrm{B})) \leqslant \mathrm{H}^{+}(\mathrm{T}(\mathrm{a}), \mathrm{T}(\mathrm{b})) .
$$

Thus,

$$
H(T(A), T(B)) \leqslant 2 H^{+}(T(A), T(B)) \leqslant 2 \alpha d(a, b) \leqslant 2 \alpha H(A, B), \quad \forall A, B \in P_{c p}(X) .
$$

(vii) By (vi) it follows that $\hat{T}$ is a self-contraction (with constant $2 \alpha<1$ ) on the complete metric space $\left(\mathrm{P}_{\mathrm{cp}}(\mathrm{X}), \mathrm{H}\right)$. By the contraction principle, we obtain that

$$
\mathrm{F}_{\hat{\mathrm{T}}}=\left\{\mathrm{A}_{\mathrm{T}}^{*}\right\} \text { and } \hat{\mathrm{T}}^{n}(\mathrm{~A}) \stackrel{\mathrm{H}}{\rightarrow} \mathrm{A}_{\mathrm{T}}^{*} \text {, as } \mathrm{n} \rightarrow \infty, \quad \text { for each } A \in \mathrm{P}_{\mathbf{c p}}(\mathrm{X}) .
$$

As a consequence of Lemma 2.1, we also get that $\hat{T}^{n}(A) \stackrel{H^{+}}{\rightarrow} A_{T}^{*}$ as $n \rightarrow \infty$, for each $A \in P_{c p}(X)$. In particular, if $A:=\{x\}$, we get that $\mathrm{T}^{\mathrm{n}}(\mathrm{x})=\hat{\mathrm{T}}^{\mathrm{n}}(\mathrm{x}) \stackrel{\mathrm{H}^{+}}{\rightarrow} \mathrm{A}_{\mathrm{T}}^{*}$ as $\mathrm{n} \rightarrow+\infty$, for each $x \in X$. Let $x \in \mathrm{F}_{\mathrm{T}}$ be arbitrary. Then $x \in \mathrm{T}(\mathrm{x}) \subset \mathrm{T}^{2}(\mathrm{x}) \subset \cdots \subset \mathrm{T}^{\mathrm{n}}(\mathrm{x}) \subset \cdots$. Hence $\mathrm{x} \in \mathrm{T}^{\mathrm{n}}(\mathrm{x})$, for each $\mathrm{n} \in \mathbb{N}^{*}$. Moreover, $\lim _{n \rightarrow+\infty} T^{n}(x)=\bigcup_{n \in \mathbb{N}^{*}} T^{n}(x)$. By $(v i)$, we immediately get that $A_{T}^{*}=\bigcup_{n \in \mathbb{N}^{*}} T^{n}(x)$. Hence

$$
\mathrm{F}_{\mathrm{T}} \subset \bigcup_{n \in \mathbb{N}^{*}} \mathrm{~T}^{\mathrm{n}}(\mathrm{x})=\mathrm{A}_{\mathrm{T}}^{*}
$$

Since $\mathrm{F}_{\mathrm{T}}$ is closed subset of the compact $A_{\mathrm{T}}^{*}$, it follows that $\mathrm{F}_{\mathrm{T}}$ is compact, too.

Some new conclusions with respect to the fixed point and the strict fixed point sets are given in our next result.

Theorem 3.12. Let $(\mathrm{X}, \mathrm{d})$ be a complete metric space and $\mathrm{T}: \mathrm{X} \rightarrow \mathrm{P}_{\mathrm{cl}}(\mathrm{X})$ be a multivalued $\left(\mathrm{H}^{+}, \alpha\right)$-contraction with $(\mathrm{SF})_{\mathrm{T}} \neq \emptyset$. Then, the following assertions hold: 
(i) $(\mathrm{SF})_{\mathrm{T}}=\left\{x^{*}\right\}$.

If additionally, $\alpha \in\left[0, \frac{1}{2}[\right.$, then

(ii) $\mathrm{F}_{\mathrm{T}}=(\mathrm{SF})_{\mathrm{T}}=\left(\mathrm{SF}_{\mathrm{T}^{\mathrm{n}}}\right)=\left\{x^{*}\right\}$, for $\mathrm{n} \in \mathbb{N}^{*}$.

(iii) $\mathrm{T}^{\mathrm{n}}(\mathrm{x}) \stackrel{\mathrm{H}^{+}}{\rightarrow}\left\{\mathrm{x}^{*}\right\}$ as $\mathrm{n} \rightarrow \infty$, for each $\mathrm{x} \in \mathrm{X}$.

(iv) Let $\mathrm{S}: \mathrm{X} \rightarrow \mathrm{P}_{\mathrm{cl}}(\mathrm{X})$ be a multivalued operator such that $\mathrm{F}_{\mathrm{S}} \neq \emptyset$ and suppose there exists $\eta>0$ such that

$$
\mathrm{H}^{+}(\mathrm{S}(\mathrm{x}), \mathrm{T}(\mathrm{x})) \leqslant \eta, \quad \forall x \in X .
$$

Then

$$
\mathrm{H}^{+}\left(\mathrm{F}_{\mathrm{S}}, \mathrm{F}_{\mathrm{T}}\right) \leqslant \frac{2 \eta}{1-2 \alpha}
$$

(v) (Well-posedness of the fixed point problem w.r.t. to $\mathrm{H}^{+}$) If $\left(\mathrm{x}_{\mathrm{n}}\right)_{\mathfrak{n} \in \mathbb{N}}$ is a sequence in $\mathrm{X}$ such that

$$
\mathrm{H}^{+}\left(\mathrm{x}_{\mathrm{n}}, \mathrm{T}\left(\mathrm{x}_{\mathrm{n}}\right)\right) \rightarrow 0 \text { as } \mathrm{n} \rightarrow \infty,
$$

then $\mathrm{x}_{\mathrm{n}} \stackrel{\mathrm{d}}{\rightarrow} \mathrm{x}^{*}$ as $\mathrm{n} \rightarrow \infty$.

(vi) (Limit shadowing property of the multivalued operator) If $\left(\mathrm{y}_{\mathfrak{n}}\right)_{\mathfrak{n} \in \mathbb{N}}$ is a sequence in $\mathrm{X}$ such that

$$
\mathrm{D}\left(\mathrm{y}_{\mathrm{n}+1}, \mathrm{~T}\left(\mathrm{y}_{\mathrm{n}}\right)\right) \rightarrow 0 \text { as } \mathrm{n} \rightarrow \infty
$$

then there exists a sequence $\left(x_{n}\right)_{n \in \mathbb{N}} \subset X$ of successive approximations for $T$, such that $\mathrm{d}\left(x_{n}, y_{n}\right) \rightarrow 0$ as $\mathrm{n} \rightarrow \infty$.

Proof.

(i) Let $x^{*} \in(\mathrm{SF})_{\mathrm{T}}$. Notice first that $(\mathrm{SF})_{\mathrm{T}}=\left\{x^{*}\right\}$. Indeed, if $z \in(\mathrm{SF})_{\mathrm{T}}$ with $z \neq x^{*}$, then $0<\mathrm{d}\left(x^{*}, z\right)=$ $\mathrm{H}^{+}\left(\mathrm{T}\left(\mathrm{x}^{*}\right), \mathrm{T}(z)\right) \leqslant \alpha \mathrm{d}\left(\mathrm{x}^{*}, z\right)$, which is a contradiction. Thus $(\mathrm{SF})_{\mathrm{T}}=\left\{\mathrm{x}^{*}\right\}$.

(ii) Suppose that $y \in F_{T}$. Then,

$$
\begin{aligned}
d\left(y, x^{*}\right) & =D\left(y, T\left(x^{*}\right)\right) \\
& \leqslant \rho\left(T(y), T\left(x^{*}\right)\right) \\
& \leqslant H\left(T(y), T\left(x^{*}\right)\right) \\
& \leqslant 2 H^{+}\left(T(y), T\left(x^{*}\right)\right) \\
& \leqslant 2 \alpha d\left(y, x^{*}\right) .
\end{aligned}
$$

Hence, $y=x^{*}$ and $\mathrm{F}_{\mathrm{T}} \subset(\mathrm{SF})_{\mathrm{T}}$. Since $(\mathrm{SF})_{\mathrm{T}} \subset \mathrm{F}_{\mathrm{T}}$, we get that $(\mathrm{SF})_{\mathrm{T}}=\mathrm{F}_{\mathrm{T}}$.

Notice now that $x^{*} \in(S F)_{T^{n}}$, for each $n \in \mathbb{N}^{*}$. Consider $y \in(S F)_{T^{n}}$, for arbitrary $n \in \mathbb{N}^{*}$. Then

$$
\begin{aligned}
d\left(x^{*}, y\right)= & H\left(T^{n}\left(x^{*}\right), T^{n}(y)\right) \\
\leqslant & 2 \alpha H\left(T^{n-1}\left(x^{*}\right), T^{n-1}(y)\right) \\
\leqslant & (2 \alpha)^{2} H\left(T^{n-2}\left(x^{*}\right), T^{n-2}(y)\right) \\
& \vdots \\
\leqslant & (2 \alpha)^{n} d\left(x^{*}, y\right) .
\end{aligned}
$$

Thus, $y=x^{*}$ and hence $(S F)_{\mathrm{T}}^{n}=\left\{x^{*}\right\}$. 
(iii) Let $x \in X$ be arbitrarily chosen. Then we have

$$
\begin{aligned}
\mathrm{H}^{+}\left(\mathrm{T}^{\mathrm{n}}(x), x^{*}\right)= & \mathrm{H}^{+}\left(\mathrm{T}^{\mathrm{n}}(x), \mathrm{T}^{\mathrm{n}}\left(x^{*}\right)\right) \\
\leqslant & \mathrm{H}\left(\mathrm{T}^{\mathrm{n}}(x), \mathrm{T}^{\mathrm{n}}\left(x^{*}\right)\right) \\
\leqslant & (2 \alpha) H\left(\mathrm{~T}^{n-1}(x), \mathrm{T}^{n-1}\left(x^{*}\right)\right) \\
& \quad \vdots \\
\leqslant & (2 \alpha)^{\mathrm{n}} \mathrm{d}\left(x, x^{*}\right) \rightarrow 0 \text { as } \mathrm{n} \rightarrow \infty .
\end{aligned}
$$

(iv) Let $y \in F_{S}$. Then

$$
\begin{aligned}
d\left(y, x^{*}\right) & \leqslant H\left(S(y), x^{*}\right) \\
& \leqslant 2 H^{+}\left(S(y), x^{*}\right) \\
& \leqslant 2\left(H^{+}(S(y), T(y))+H^{+}\left(T(y), x^{*}\right)\right) \\
& \leqslant 2\left(\eta+\alpha d\left(y, x^{*}\right)\right) .
\end{aligned}
$$

Thus, $d\left(y, x^{*}\right) \leqslant \frac{2 \eta}{1-2 \alpha}$. The conclusion follows by the relations

$$
H^{+}\left(F_{S}, F_{T}\right) \leqslant \sup _{y \in F_{S}} d\left(y, x^{*}\right) \leqslant \frac{2 \eta}{1-2 \alpha} .
$$

(v) Let $\left(x_{n}\right)_{n \in \mathbb{N}}$ be a sequence in $X$ such that $H^{+}\left(x_{n}, T\left(x_{n}\right)\right) \rightarrow 0$ as $n \rightarrow \infty$. Then,

$$
\begin{aligned}
d\left(x_{n}, x^{*}\right) & \leqslant D\left(x_{n}, T\left(x_{n}\right)\right)+H_{d}\left(T\left(x_{n}\right), T\left(x^{*}\right)\right) \\
& \leqslant H_{d}\left(x_{n}, T\left(x_{n}\right)\right)+2 H^{+}\left(T\left(x_{n}\right), T\left(x^{*}\right)\right) \\
& \leqslant 2 H^{+}\left(x_{n}, T\left(x_{n}\right)\right)+2 k d\left(x_{n}, x^{*}\right) .
\end{aligned}
$$

Then

$$
\mathrm{d}\left(\mathrm{x}_{\mathrm{n}}, \mathrm{x}^{*}\right) \leqslant \frac{2}{1-2 \mathrm{k}} \mathrm{H}^{+}\left(\mathrm{x}_{\mathrm{n}}, \mathrm{T}\left(\mathrm{x}_{\mathrm{n}}\right)\right) \rightarrow 0 \text { as } \mathrm{n} \rightarrow \infty .
$$

(vi) Let $\left(y_{n}\right)_{n \in \mathbb{N}}$ be a sequence in $X$ such that

$$
\mathrm{D}\left(\mathrm{y}_{\mathrm{n}+1}, \mathrm{~T}\left(\mathrm{y}_{\mathrm{n}}\right)\right) \rightarrow 0 \text { as } \mathrm{n} \rightarrow \infty .
$$

Then, there exists $u_{n} \in T\left(y_{n}\right), n \in \mathbb{N}$ such that

$$
\mathrm{d}\left(\mathrm{y}_{\mathrm{n}+1}, \mathrm{u}_{\mathrm{n}}\right) \rightarrow 0 \text { as } \mathrm{n} \rightarrow \infty
$$

We shall prove that $d\left(y_{n}, x^{*}\right) \rightarrow 0$ as $n \rightarrow \infty$.

We successively have

$$
\begin{aligned}
\mathrm{d}\left(x^{*}, y_{n+1}\right) \leqslant & H\left(x^{*}, T\left(y_{n}\right)\right)+D\left(y_{n+1}, T\left(y_{n}\right)\right) \\
\leqslant & 2 H^{+}\left(x^{*}, T\left(y_{n}\right)\right)+D\left(y_{n+1}, T\left(y_{n}\right)\right) \\
\leqslant & 2 \alpha d\left(x^{*}, y_{n}\right)+D\left(y_{n+1}, T\left(y_{n}\right)\right) \\
\leqslant & 2 \alpha\left[2 \alpha d\left(x^{*}, y_{n-1}\right)+D\left(y_{n}, T\left(y_{n-1}\right)\right)\right] D\left(y_{n+1}, T\left(y_{n}\right)\right) \\
& \quad \vdots \\
\leqslant & (2 \alpha)^{n+1} d\left(x^{*}, y_{0}\right)+(2 \alpha)^{n} D\left(y_{1} T\left(y_{0}\right)\right)+\cdots+D\left(y_{n+1}, T\left(y_{n}\right)\right) .
\end{aligned}
$$

By Lemma 3.10, the right hand side tends to 0 as $n \rightarrow \infty$. Thus, $d\left(x^{*}, y_{n+1}\right) \rightarrow 0$ as $n \rightarrow \infty$. 
On the other hand, by the fact that $T$ is an MWP operator, we know that there exists a sequence $\left(x_{n}\right)_{n \in \mathbb{N}}$ of successive approximations for $T$ starting from arbitrary $\left(x_{0}, x_{1}\right) \in \operatorname{Graph}(T)$ which converges to a fixed point $x^{*} \in X$ of the operator $T$. Since the fixed point is unique, we get that $d\left(x_{n}, x^{*}\right) \rightarrow 0$ as $n \rightarrow \infty$. Hence, for such a sequence $\left(x_{n}\right)_{n} \in \mathbb{N}$, we have

$$
d\left(y_{n}, x_{n}\right) \leqslant d\left(y_{n}, x^{*}\right)+d\left(x^{*}, x_{n}\right) \rightarrow 0, \text { as } n \rightarrow \infty .
$$

Remark 3.13. Similar results can be given for the case of multivalued $\varphi$-contraction w.r.t. $\mathrm{H}^{+}$. The results of this type can be viewed as generalizations of some theorems given in [7].

We now give an application of the above results to the continuous dependence of the solution set for a Cauchy problem associated to a differential inclusion, with respect to the initial condition. The existence of a solution to the initial value problem

$$
\left\{\begin{array}{l}
\dot{x}(\mathrm{t}) \in \mathrm{T}(\mathrm{t}, x(\mathrm{t})) \\
x(0)=\mathrm{b}
\end{array}\right.
$$

was proved by Filippov [3] and Castaing [2] under certain conditions on T.

In [10], Markin proved a stability theorem on the set of solutions to (3.4) using the $\mathrm{L}^{2}$ norm, while Lim [9] proved a stability result in terms of the Hausdorff-Pompeiu functional. We will prove now a similar theorem using the sup norm and the Pompeiu functional generated by it.

We recall first the concept of solution.

Definition 3.14. Let $D=[0, a] \times \mathbb{R}^{n}$ and $T: D \rightarrow P\left(\mathbb{R}^{n}\right)$ be a continuous operator. Then, a mapping $x:[0, a] \rightarrow \mathbb{R}^{n}$ is said to be a solution of the differential inclusion (3.4), if $x$ is an absolutely continuous mapping and $x^{\prime}(t) \in T(t, x(t))$, a.e. on $[0, a]$.

Let $B$ be an origin-centered closed ball in $\mathrm{R}^{n}$ and $\mathrm{P}_{\mathrm{cl}, \mathrm{cv}}(\mathrm{B})$ endowed with the $\mathrm{H}^{+}$metric generated by the Euclidean norm $\|\cdot\|$ of $R^{n}$. Let $C[0, a]$ be the set of the continuous maps of $[0, a]$ into $R^{n}$ with the sup norm $\|\cdot\|_{C}$.

Assume that $T$ is a continuous map of $[0, a] \times B$ into $P_{c l, c v}(B)$ satisfying, for some $k>0$, the condition

$$
H^{+}(T(t, u), T(t, v)) \leqslant k\|u-v\|_{C}, \quad \forall t \in[0, a], u, v \in B .
$$

For $b \in B$, we will denote $S(b)$ the set of solutions of (3.4) on $[0, a] . S(b)$ is nonempty and compact, by [3] and [2].

Theorem 3.15. If the following conditions hold:

1. $\mathrm{T}:[0, \mathrm{a}] \times \mathrm{B} \rightarrow \mathrm{P}_{c l, c v}(\mathrm{~B})$ is continuous;

2. there exists $\mathrm{k}>0$ such that

$$
\mathrm{H}^{+}(\mathrm{T}(\mathrm{t}, \mathrm{u}), \mathrm{T}(\mathrm{t}, v)) \leqslant \mathrm{k}\|\mathrm{u}-v\|_{\mathrm{C}}, \quad \forall \mathrm{t} \in[0, \mathrm{a}], \quad \forall \mathrm{u}, v \in \mathrm{B} \subseteq \mathbb{R}^{\mathrm{n}} ;
$$

3. $2 k a<1$,

then $\mathrm{S}(\mathrm{b})$ is continuous from $\mathrm{B}$ into the family of nonempty compact subsets of $\mathrm{C}\left[0\right.$, a equipped with the $\mathrm{H}^{+}$metric.

Proof. Suppose $b_{n} \rightarrow b_{0}$. For $x \in C[0, a]$, define

$$
\mathrm{F}(\mathrm{b}, \mathrm{x})=\left\{\mathrm{y} \in[0, \mathrm{a}]: \mathrm{y}(\mathrm{t})=\mathrm{b}+\int_{0}^{\mathrm{t}} z(\mathrm{~s}) \mathrm{d} s, z(\mathrm{~s}) \in \mathrm{T}(\mathrm{s}, x(\mathrm{~s}))\right\} .
$$

Let $F_{n}(x)=F\left(b_{n}, x\right), n=0,1,2, \cdots$. Since $F_{0}(x)=b_{n}-b_{0}+F_{n}(x)$ it is obvious that $F_{n}(x)$ converges uniformly to $F_{0}(x)$. $F_{n}(x)$ is compact convex for each $x$ and $n$. Given any pair $x_{1}, x_{2} \in C[0, a]$ and $y_{1} \in F\left(b, x_{1}\right)$, let

$$
y_{1}(t)=b+\int_{0}^{t} r_{1}(s) d s, r_{1}(s) \in T\left(s, x_{1}(s)\right)
$$


Define $r_{2}(s)$ to be the point in $T\left(s, x_{2}(s)\right)$ nearest to $r_{1}(s)$, i.e., $r_{2} \in T\left(s, x_{2}(s)\right)$ and

$$
\left\|\mathrm{r}_{1}(\mathrm{~s})-\mathrm{r}_{2}(\mathrm{~s})\right\|=\min \left\{\left\|\mathrm{r}_{1}(\mathrm{~s})-z\right\| \mid z \in \mathrm{T}\left(\mathrm{s}, \mathrm{x}_{2}(\mathrm{~s})\right)\right\} \text {. }
$$

It follows from the measurability of $r_{1}(s)$ and the continuity of $T\left(s, x_{2}(s)\right)$ and the nearest point projection that $r_{2}(s)$ is measurable.

Setting

$$
y_{2}(t)=b+\int_{0}^{t} r_{2}(s) d s, \quad r_{2}(s) \in T\left(s, x_{2}(s)\right)
$$

we have

$$
\begin{aligned}
\left\|y_{2}-y_{1}\right\| & \leqslant \int_{0}^{a}\left\|r_{1}(s)-r_{2}(s)\right\| d s \\
& =\int_{0}^{a} \min \left\{\left\|r_{1}(s)-z\right\|, z \in T\left(s, x_{2}(s)\right)\right\} \\
& =\int_{0}^{a} D_{\|\cdot\|}\left(r_{1}(s), T\left(s, x_{2}(s)\right)\right) d s \\
& \leqslant \int_{0}^{a} H_{d}\left(T\left(s, x_{1}(s)\right), T\left(s, x_{2}(s)\right)\right) d s \\
& \leqslant \int_{0}^{a} 2 H^{+}\left(T\left(s, x_{1}(s)\right), T\left(s, x_{2}(s)\right)\right) d s \leqslant 2 k \int_{0}^{a}\left\|x_{1}(s)-x_{2}(s)\right\| d s \\
& \leqslant 2 k a\left\|x_{1}-x_{2}\right\|_{C} .
\end{aligned}
$$

Thus $F_{n}$ are $\lambda$-contraction with $\lambda=2 k a<1$.

By (iv) of Theorem 3.11, $\mathrm{F}\left(\mathrm{T}_{\mathrm{n}}\right) \stackrel{\mathrm{H}^{+}}{\rightarrow} \mathrm{F}\left(\mathrm{T}_{0}\right)$ i.e., $\mathrm{S}\left(\mathrm{b}_{\mathrm{n}}\right) \stackrel{\mathrm{H}^{+}}{\rightarrow} \mathrm{S}\left(\mathrm{b}_{0}\right)$.

More generally, we have the following result.

Theorem 3.16. For each $\mathrm{n}=0,1,2, \cdots$, let $\mathrm{T}_{\mathrm{n}}$ be a continuous map of $[0, \mathrm{a}] \times \mathrm{B}$ into $\mathrm{C}(\mathrm{B})$ satisfying, for some $k>0$, the condition

$$
\mathrm{H}^{+}\left(\mathrm{T}_{\mathrm{n}}(\mathrm{t}, \mathrm{u}), \mathrm{T}_{\mathrm{n}}(\mathrm{t}, v)\right) \leqslant \mathrm{k}\|\mathrm{u}-v\|_{\mathrm{C}}, \quad \forall \mathrm{t} \in[0, \mathrm{a}], \quad \forall \mathrm{u}, v \in \mathrm{B} .
$$

Assume that $\mathrm{T}_{\mathrm{n}} \rightarrow \mathrm{T}_{0}$ uniformly on $[0, \mathrm{a}] \times \mathrm{B}$. For each $\mathrm{b} \in \mathrm{B}$ and $\mathrm{n}=0,1,2, \cdots$. Let $\mathrm{S}_{\mathrm{n}}(\mathrm{b})$ be the set of solutions of

$$
\left\{\begin{array}{l}
\dot{x}(t) \in T_{n}(t, x(t)), \\
x(0)=b
\end{array}\right.
$$

If $2 \mathrm{ka}<1$ and $\mathrm{b}_{\mathrm{n}} \rightarrow \mathrm{b}_{0}$ in $\mathrm{B}$, then $\mathrm{S}_{\mathrm{n}}\left(\mathrm{b}_{\mathrm{n}}\right) \rightarrow \mathrm{S}_{0}\left(\mathrm{~b}_{0}\right)$.

Proof. Let $b_{n} \rightarrow b_{0}$. For $x_{n} \in C[0, a]$, define

$$
\mathrm{F}\left(\mathrm{b}, x_{\mathrm{n}}\right)=\left\{\mathrm{y}_{\mathrm{n}} \in[0, \mathrm{a}]: \mathrm{y}_{\mathrm{n}}(\mathrm{t})=\mathrm{b}+\int_{0}^{\mathrm{t}} z_{\mathrm{n}}(\mathrm{s}) \mathrm{ds}, z_{\mathrm{n}}(\mathrm{s}) \in \mathrm{T}_{\mathrm{n}}(\mathrm{s}, \mathrm{x}(\mathrm{s}))\right\} .
$$

Let $F_{n}\left(x_{n}\right)=F\left(b_{n}, x_{n}\right), n=0,1,2, \cdots$. Since $F_{0}(x)=b_{n}-b_{0}+F_{n}(x)$ it is obvious that $F_{n}(x)$ converges uniformly to $F_{0}(x) . F_{n}(x)$ is compact convex for each $x_{n}$ and $n$.

Given any pair $x_{n}^{(1)}, x_{n}^{(2)} \in C[0, a]$ and $y_{n}^{(1)} \in F\left(b, x_{n}^{(1)}\right)$, let

$$
y_{n}^{(1)}(t)=b+\int_{0}^{t} r_{n}^{(1)}(s), r_{n}^{(1)}(s) \in T_{n}\left(s, x_{n}^{(1)}(s)\right) d s .
$$

Define $r_{n}^{(2)}(s)$ to be the point in $T_{n}\left(s, x_{n}^{(2)}(s)\right)$ nearest to $r_{n}^{(1)}(s)$, i.e., $r_{n}^{(2)} \in T_{n}\left(s, x_{n}^{(2)}(s)\right)$ and

$$
\left\|r_{n}^{(1)}(s)-r_{n}^{(2)}(s)\right\|=\min \left\{\left\|r_{n}^{(1)}(s)-z_{n}\right\| \mid z_{n} \in T_{n}\left(s, x_{n}^{(2)}(s)\right)\right\}
$$

It follows from the measurability of $r_{n}^{(1)}(s)$ and the continuity of $T_{n}\left(s, \chi_{n}^{2}(s)\right)$ and the nearest point pro- 
jection that $r_{n}^{(2)}(s)$ is measurable.

Setting

$$
y_{n}^{(2)}(t)=b+\int_{0}^{t} r_{n}^{(2)}(s) d s, \quad r_{n}^{(2)}(s) \in T_{n}\left(s, x_{n}^{(2)}(s)\right)
$$

we have

$$
\left\|y_{n}^{(2)}-y_{n}^{(1)}\right\| \leqslant 2 k a\left\|x_{n}^{(1)}-x_{n}^{(2)}\right\|_{c} .
$$

Thus $F_{n}$ are $\lambda$-contraction with $\lambda=2 k a<1$.

By (iv) of Theorem 3.11, we have $\mathrm{F}\left(\mathrm{T}_{\mathfrak{n}}\right) \stackrel{\mathrm{H}^{+}}{\rightarrow} \mathrm{F}\left(\mathrm{T}_{0}\right)$, i.e., $\mathrm{S}_{\mathfrak{n}}\left(\mathrm{b}_{\mathfrak{n}}\right) \stackrel{\mathrm{H}^{+}}{\rightarrow} \mathrm{S}_{\mathfrak{n}}\left(\mathrm{b}_{0}\right)$.

Next, an application to Ulam-Hyers stability of the inclusion $x \in T(x)((v)$ of Theorem 3.11) is given. The notion of Ulam-Hyers stability for a differential inclusion is defined as follows.

Definition 3.17. Let

$$
x^{\prime} \in T(t, x(t)), \quad t \in[0, a],
$$

and $\mathrm{T}:[0, \mathrm{a}] \times \mathbb{R}^{\mathrm{n}} \rightarrow \mathrm{P}_{\mathrm{cl}, \mathrm{cv}}\left(\mathbb{R}^{\mathrm{n}}\right)$ be a continuous operator. We say that (3.5) is Ulam-Hyers stable if for any $\epsilon>0$, any $y \in C[0, a]$ and any $\epsilon$-solution of (3.5) (which means that

$$
\left.D\left(y(t), y(0)+\int_{0}^{t} T(s, y(s)) d s\right) \leqslant \epsilon, \quad t \in[0, a]\right),
$$

there exists a solution $x^{*}$ of (3.5) and $c>0$ such that $\left\|x^{*}-y\right\| \leqslant c \cdot \epsilon$.

Definition 3.18. Let $F:[0, a] \rightarrow P_{c} l\left(\mathbb{R}^{n}\right)$ be a measurable multivalued operator. If $L^{1}\left([0, a], \mathbb{R}^{n}\right)$ denotes the set of all measurable and integrable mappings from $[0, a]$ to $\mathbb{R}^{n}$, then $S_{F}$ will denote the set of all integrable selections of $F$, i.e.,

$$
S_{F}:=\left\{f \in L^{1}\left([0, a], \mathbb{R}^{n}\right) \mid f(t) \in F(t), \text { a.e. } t \in[0, a]\right\} .
$$

Remark 3.19. In particular, if $x:[0, a] \rightarrow \mathbb{R}^{n}$ and $\mathrm{T}:[0, \mathrm{a}] \times \mathbb{R}^{\mathrm{n}} \rightarrow \mathrm{P}_{\mathrm{cl}}\left(\mathbb{R}^{\mathrm{n}}\right)$, then the set of all integrable selections of $\mathrm{T}$ will be denoted by

$$
S_{T(\cdot, x(\cdot))}:=\left\{f \in L^{1}\left([0, a], \mathbb{R}^{n}\right) \mid f(t) \in T(t, x(t)) \text { a.e. } t \in[0, a]\right\} .
$$

Theorem 3.20. Let us consider the inclusion (3.5). We assume:

(a) $\mathrm{T}:[0, \mathrm{a}] \times \mathbb{R}^{\mathrm{n}} \rightarrow \mathrm{P}_{c l, c v}\left(\mathbb{R}^{\mathrm{n}}\right)$ is a continuous, measurable and integrably bounded multivalued operator.

(b) There exists $\mathrm{L}>0$ such that

$$
H^{+}\left(T\left(t, u_{1}\right), T\left(t, u_{2}\right)\right) \leqslant L\left\|u_{1}-u_{2}\right\|, \quad \forall\left(t, u_{1}\right),\left(t, u_{2}\right) \in[0, a] \times \mathbb{R}^{n} .
$$

Then the differential inclusion (3.5) with initial condition $x(0)=x^{0}$ has at least one solution. Moreover the differential inclusion (3.5) is Ulam-Hyers stable.

Proof. Let us define $\mathrm{U}: \mathrm{C}[0, \mathrm{a}] \rightarrow \mathrm{P}(\mathrm{C}[0, \mathrm{a}]), \mathrm{u} \rightarrow \mathrm{U} x$ and $\mathrm{U} x(\mathrm{t}):=\mathrm{b}+\int_{0}^{\mathrm{t}} \mathrm{T}(\mathrm{s}, \mathrm{x}(\mathrm{s})) \mathrm{ds}, \mathrm{t} \in[0, \mathrm{a}]$. We notice that, since $T$ is u.s.c., (3.5) is equivalent with the fixed point problem

$$
x \in \mathrm{U} x .
$$

We will show that the fixed point problem (3.6) is Ulam-Hyers stable.

Let $y, z \in C[a, b]$ and $u_{1} \in U x$. Then $u_{1} \in C[0, a]$ and

$$
\mathrm{u}_{1}(\mathrm{t}) \in x(0)+\int_{0}^{t} \mathrm{~T}(\mathrm{~s}, x(\mathrm{~s})) \mathrm{ds} \text { a.e. on }[0, \mathrm{a}] \text {. }
$$


It follows that there is a mapping $k_{y} \in S_{T(\cdot, y(\cdot))}$ such that

$$
u_{1}(t)=x(0)+\int_{0}^{t} k_{x}(s) d s \text { a.e. on }[0, a]
$$

Since

$$
H^{+}(T(t, x(t)), T(t, y(t))) \leqslant L\|x(t)-y(t)\|,
$$

one obtains that there exists $w \in \mathrm{T}(\mathrm{t}, \mathrm{y}(\mathrm{t}))$ such that

$$
\left\|k_{x}(t)-w\right\| \leqslant H(T(t, x(t)), T(t, y(t))) \leqslant 2 H^{+}(T(t, x(t)), T(t, y(t))) \leqslant 2 L\|x(t)-y(t)\| .
$$

Thus the multivalued operator $G$ defined by $G(t)=T_{y}(t) \cup K(t)$ (where $T_{y}(t)=T(t, y(t)$ ) and

$$
K(t)=\left\{w \mid\left\|k_{x}(t)-w\right\| \leqslant 2 L\|x(t)-y(t)\|\right\},
$$

has nonempty values and is measurable.

Let $k_{z}$ be a measurable selection for $G$ (which exists by Kuratowski and Ryll Nardzewski's selection theorem). Then $k_{y}(t) \in T(t, y(t))$ and

$$
\left\|k_{x}(t)-k_{y}(t)\right\| \leqslant 2 L\|x(t)-y(t)\| \text {, a.e. on }[0, a] .
$$

Define $u_{2}=x(0)+\int_{0}^{t} k_{y}(s) d s$. It follows that $u_{2} \in U y$ and

$$
\begin{aligned}
\left\|\mathrm{u}_{1}(\mathrm{t})-\mathrm{u}_{2}(\mathrm{t})\right\| & \leqslant \int_{0}^{\mathrm{t}}\left\|\mathrm{k}_{\mathrm{x}}(\mathrm{s})-\mathrm{k}_{\mathrm{y}}(\mathrm{s})\right\| \mathrm{ds} \\
& \leqslant 2 \mathrm{~L} \int_{0}^{\mathrm{t}}\|x(s)-\mathrm{y}(\mathrm{s})\| \mathrm{ds} \\
& =2 \mathrm{~L} \int_{0}^{\mathrm{t}}\|x(s)-\mathrm{y}(\mathrm{s})\| \cdot \mathrm{e}^{-\tau(s-\mathrm{a})} \cdot \mathrm{e}^{\tau(\mathrm{s}-\mathrm{a})} \mathrm{ds} \\
& \leqslant 2 \mathrm{~L}\|x-y\|_{B} \int_{0}^{\mathrm{t}} \mathrm{e}^{\tau(s-\mathrm{a})} \mathrm{ds} \\
& \leqslant \frac{2 \mathrm{~L}}{\tau} e^{\tau(s-a)}\|x-y\|_{B} .
\end{aligned}
$$

Here $\|\cdot\|_{B}$ denotes the Bielecki-type norm on $C[0, a]$. Finally, we have that

$$
\left\|u_{1}-u_{2}\right\|_{B} \leqslant \frac{2 L}{\tau}\|x-y\|_{B} .
$$

From this and the analogous inequality obtained by interchanging the roles $x$ and $y$ and adding them and then dividing by 2 we get that

$$
\mathrm{H}^{+}(\mathrm{U} x, \mathrm{U} y) \leqslant \frac{2 \mathrm{~L}}{\tau}\|x-y\|_{\mathrm{B}}, \quad \forall x, y \in \mathrm{C}[0, \mathrm{a}] .
$$

Taking $\tau>2 \mathrm{~L}$, it follows that $\mathrm{U}$ is multivalued $\left(\mathrm{H}^{+}, \alpha\right)$-contraction.

\section{Continuation results for multivalued $\left(\mathrm{H}^{+}, \alpha\right)$-contractions}

In this section, we present a local result and a continuation result for a special kind of multivalued $\left(\mathrm{H}^{+}, \alpha\right)$-contractions. Following Kirk and Shahzad ([6]), we will replace the second condition of the Definition 1.2: 
$(*)$ for every $x \in X, y \in T(x)$ and for every $\epsilon>0$ there exists $z$ in $T(y)$ such that

$$
d(y, z) \leqslant H^{+}(T(x), T(y))+\varepsilon,
$$

with the following one:

$(* *)$ for every $x \in X$ and every $y \in T(x)$ we have that

$$
D(y, T(y)) \leqslant H^{+}(T(x), T(y)) .
$$

Notice that $(* *)$ implies $(*)$. Moreover if we consider the following condition:

$(* * *)$ for every $\epsilon>0$, for every $x \in X, y \in T(x)$ there exists $z$ in $T(y)$ such that

$$
d(y, z) \leqslant H^{+}(T(x), T(y))+\varepsilon .
$$

Then it is easy to see that $(* *)$ is equivalent with $(* * *)$. In this last case, we also notice that for each $x \in X$ and every $y \in T(x)$ we have $\rho(T(x), T(y)) \leqslant H^{+}(T(x), T(y))$. As a consequence, $\rho(T(x), T(y)) \leqslant$ $\rho(\mathrm{T}(\mathrm{y}), \mathrm{T}(\mathrm{x}))$ and so

$$
\mathrm{H}^{+}(\mathrm{T}(\mathrm{x}), \mathrm{T}(\mathrm{y})) \leqslant \rho(\mathrm{T}(\mathrm{y}), \mathrm{T}(\mathrm{x})), \quad \forall x \in X, \quad \mathrm{y} \in \mathrm{T}(\mathrm{x}) .
$$

Homotopy results for multivalued operators of contractive types are well-known in the literature, see $[4,5,8]$. This approach is applied in all cases on a local fixed point theorem. The first result of this section is the following local fixed point theorem.

Theorem 4.1. Let $(\mathrm{X}, \mathrm{d})$ be a complete metric space, $\mathrm{x}_{0} \in \mathrm{X}, \mathrm{r}>0$ and $\mathrm{T}: \tilde{\mathrm{B}}\left(\mathrm{x}_{0}, \mathrm{r}\right) \rightarrow \mathrm{P}_{\mathrm{cl}}(\mathrm{X})$ is a multivalued operator. We suppose that:

(i) $T$ is a multivalued $\left(\mathrm{H}^{+}, \alpha\right)$-contraction, i.e., $\left.\alpha \in\right] 0,1[$ and

$$
H^{+}(T(x), T(y)) \leqslant \alpha d(x, y), \quad \forall x, y \in X
$$

(ii) for every $\mathrm{x} \in \mathrm{X}$ and every $\mathrm{y} \in \mathrm{T}(\mathrm{x})$ we have that $\mathrm{D}(\mathrm{y}, \mathrm{T}(\mathrm{y})) \leqslant \mathrm{H}^{+}(\mathrm{T}(\mathrm{x}), \mathrm{T}(\mathrm{y}))$;

(iii) $\mathrm{D}\left(\mathrm{x}_{0}, \mathrm{~T}\left(\mathrm{x}_{0}\right)\right)<(1-\alpha) \mathrm{r}$.

Then, there exists $x^{*} \in \tilde{\mathrm{B}}\left(\mathrm{x}_{0}, \mathrm{r}\right)$ such that $\mathrm{x}^{*} \in \mathrm{T}\left(\mathrm{x}^{*}\right)$.

Proof. Notice first that, by (iii), we can find an element $x_{1} \in \mathrm{T}\left(\mathrm{x}_{0}\right)$ such that $\mathrm{d}\left(\mathrm{x}_{0}, \mathrm{x}_{1}\right)<(1-\alpha) \mathrm{r}$. Clearly $x_{1} \in \tilde{B}\left(x_{0}, r\right)$. Now, for arbitrary $\epsilon>0$, by (ii) and (i), it follows that we can choose $x_{2} \in \mathrm{T}\left(x_{1}\right)$ such that

$$
\mathrm{d}\left(\mathrm{x}_{1}, \mathrm{x}_{2}\right)<\mathrm{D}\left(\mathrm{x}_{1}, \mathrm{~T}\left(\mathrm{x}_{1}\right)\right)+\epsilon \leqslant \mathrm{H}^{+}\left(\mathrm{T}\left(\mathrm{x}_{0}\right), \mathrm{T}\left(\mathrm{x}_{1}\right)\right)+\epsilon \leqslant \alpha \mathrm{d}\left(\mathrm{x}_{0}, \mathrm{x}_{1}\right)+\epsilon .
$$

If we take $\epsilon:=\alpha\left[(1-\alpha) r-d\left(x_{0}, x_{1}\right)\right]>0$, then we get that

$$
\mathrm{d}\left(\mathrm{x}_{1}, \mathrm{x}_{2}\right)<\alpha(1-\alpha) \mathrm{r} .
$$

Moreover $d\left(x_{2}, x_{0}\right) \leqslant d\left(x_{0}, x_{1}\right)+d\left(x_{1}, x_{2}\right)<(1-\alpha) r+\alpha(1-\alpha) r=\left(1-\alpha^{2}\right) r$, proving that $x_{2} \in \tilde{B}\left(x_{0}, r\right)$. Using this procedure (taking at each step $k \geqslant 2$, for the construction of $x_{k}$, the value of $\epsilon$ as $\left.\epsilon_{k}:=\alpha\left[\alpha^{k-2}(1-\alpha) r-d\left(x_{k-2}, x_{k-1}\right)\right]\right)$, we obtain a sequence $\left(x_{n}\right)_{n \in \mathbb{N}}$ having the properties:

(1) $d\left(x_{0}, x_{n}\right)<\left(1-\alpha^{n}\right) r$, for each $n \in \mathbb{N}^{*}$ (i.e., $x_{n} \in \tilde{B}\left(x_{0}, r\right)$, for each $n \in \mathbb{N}^{*}$ );

(2) $x_{n+1} \in T\left(x_{n}\right)$, for each $n \in \mathbb{N}$;

(3) $d\left(x_{n}, x_{n+1}\right)<\alpha^{n}(1-\alpha) r$, for each $n \in \mathbb{N}$. 
Then, by (3), we get that the sequence $\left(x_{n}\right)_{n \in \mathbb{N}}$ is Cauchy in $(X, d)$ and hence it converges in $(X, d)$ to some $x^{*} \in \tilde{B}\left(x_{0}, r\right)$. By Theorem 2.13, we have that $T: \tilde{B}\left(x_{0}, r\right) \rightarrow P_{c l}(X)$ has closed graph, thus we immediately get, by (2), that $x^{*} \in T\left(x^{*}\right)$ as $n \rightarrow \infty$.

Theorem 4.2. Let $(\mathrm{X}, \mathrm{d})$ be a complete metric space. Let $\mathrm{U}$ be an open subset of $(\mathrm{X}, \mathrm{d})$. Let $\mathrm{G}: \mathrm{U} \times[0,1] \rightarrow \mathrm{P}(\mathrm{X})$ be a multivalued operator such that the following conditions are satisfied:

1. $x \neq \mathrm{G}(\mathrm{x}, \mathrm{t})$ for each $\mathrm{x} \in \mathrm{\partial B}$ and each $\mathrm{t} \in[0,1]$;

2. there exists $\alpha \in[0,1[$ such that for each $\mathrm{t} \in[0,1]$ and each $\mathrm{x}, \mathrm{y} \in \mathrm{U}$ we have

$$
H^{+}(G(x, t), G(y, t)) \leqslant \alpha d(x, y) ;
$$

3. there exists a continuous increasing function $\phi:[0,1] \rightarrow \mathbb{R}$ such that

$$
\mathrm{H}^{+}(\mathrm{G}(\mathrm{x}, \mathrm{t}), \mathrm{G}(\mathrm{x}, \mathrm{s}))<|\phi(\mathrm{t})-\phi(\mathrm{s})|, \quad \forall \mathrm{t}, \mathrm{s} \in[0,1], \mathrm{t} \neq \mathrm{s}, \quad \forall x \in \mathrm{U} ;
$$

4. $\mathrm{G}: \mathrm{U} \times[0,1] \rightarrow \mathrm{P}((\mathrm{X}, \mathrm{d}))$ is closed.

Then $\mathrm{G}(\cdot, 0)$ has a fixed point if and only if $\mathrm{G}(\cdot, 1)$ has a fixed point.

Proof. Let us consider the set $\mathrm{Q}=\{(\mathrm{t}, \mathrm{x}) \in[0,1] \times \mathrm{U}: x \in \mathrm{G}(\mathrm{x}, \mathrm{t})\}$. Clearly $\mathrm{Q} \neq \emptyset$, since $(0, z) \in \mathrm{Q}$ where $z \in \mathrm{G}(z, 0)$. On $\mathrm{Q}$ we define the partial order

$$
(t, x) \leqslant(s, y) \text { if and only if } t \leqslant s \text { and } d(x, y) \leqslant \frac{2}{1-\alpha}(\phi(s)-\phi(t))
$$

Let $P$ be a totally ordered subset of $Q$. Define $t^{*}=\sup \{t:(t, x) \in P\}$.

Taking a sequence $\left\{\left(t_{n}, x_{n}\right)\right\}$ in $P$ such that

$$
\left(t_{n}, x_{n}\right) \leqslant\left(t_{n+1}, x_{n+1}\right) \text { and } t_{n} \rightarrow t^{*} \text { as } n \rightarrow \infty .
$$

We have

$$
d\left(x_{m}, x_{n}\right) \leqslant \frac{2}{1-\alpha}\left(\phi\left(t_{m}\right)-\phi\left(t_{n}\right)\right), \quad \text { for } m>n, \quad m, n \in \mathbb{N}^{*} .
$$

Thus, $\left\{x_{n}\right\}$ is a Cauchy sequence, and hence converges to some $x \in \tilde{U}$. Since $x_{n} \in G\left(x_{n}, t_{n}\right), n \in \mathbb{N}^{*}$ and $\mathrm{G}$ is closed, we have $x^{*} \in \mathrm{G}\left(\mathrm{x}^{*}, \mathrm{t}^{*}\right)$. Thus $\left(\mathrm{t}^{*}, \mathrm{x}^{*}\right) \in \mathrm{Q}$.

Since $P$ is totally ordered we get $(t, x) \leqslant\left(t^{*}, x^{*}\right)$ for each $(t, x) \in P$. That means that $\left(t^{*}, x^{*}\right)$ is a bound of $P$. It follows from Zorn's Lemma that $Q$ admits a maximal element $\left(t_{0}, x_{0}\right) \in Q$.

To complete the proof, we have to show that $t_{0}=1$. Suppose this is false. Then, we can choose $r>0$ and $t \in\left(t_{0}, 1\right]$ such that $\tilde{B}\left(x_{0}, r\right)$ and $r:=\frac{2}{1-\alpha}\left(\phi(t)-\phi\left(t_{0}\right)\right)$. It follows that

$$
\begin{aligned}
D\left(x_{0}, G\left(x_{0}, t\right)\right) & \leqslant \rho\left(G\left(x_{0}, t_{0}\right), G\left(x_{0}, t\right)\right) \\
& \leqslant H\left(G\left(x_{0}, t_{0}\right), G\left(x_{0}, t\right)\right) \\
& \leqslant 2 H^{+}\left(G\left(x_{0}, t_{0}\right), G\left(x_{0}, t\right)\right) \\
& <\phi(t)-\phi\left(t_{0}\right)=(1-\alpha) r .
\end{aligned}
$$

Since $\tilde{B}\left(x_{0}, r\right) \subset U$, the multivalued operator $G(\cdot, t): \tilde{B}\left(x_{0}, r\right) \rightarrow P_{c l}(X)$ satisfies, for all $t \in[0,1]$ the assumptions of Theorem 4.1. Hence, for all $t \in[0,1]$, there exists $x \in \tilde{B}\left(x_{0}, r\right)$ such that $x \in G(x, t)$. Thus $(t, x) \in Q$.

Since $d\left(x_{0}, x\right) \leqslant r=\frac{2}{1-\alpha}\left(\phi(t)-\phi\left(t_{0}\right)\right)$ we immediately get $\left(t_{0}, x_{0}\right)<(t, x)$. This is a contradiction with the maximality of $\left(t_{0}, x_{0}\right)$.

Conversely, if $G(\cdot, 1)$ has a fixed point, then putting $t:=1-t$ and using the first part of the proof we get the conclusion. 


\section{Acknowledgment}

This paper is a result of a doctoral research made possible by the financial support of the Sectoral Operational Programme for Human Resources Development 2007-2013, co-financed by the European Social Fund, under the project POSDRU/159/1.5/S/137750 - " Doctoral and postdoctoral programs support for increasing research competitiveness in the field of exact sciences ".

\section{References}

[1] J.-P. Aubin, H. Frankowska, Set-Valued Analysis, Birkhauser, Boston, (1990). 2.9, 2.10, 2.11, 2.12

[2] C. Castaing, Sur les equations differentielles multivoques, C. R. Acad. Sci. Paris, 263 (1966), 63-66. 3, 3

[3] A. F. Filippov, Classical solutions of differential equations with multivalued right-hand side, SIAM J. Control, 5 (1967), 609-621. 3, 3

[4] M. Frigon, On continuation methods for contractive and nonexpansive mappings.Recent advances on metric fixed point theory, Univ. Sevilla, Seville, (1996). 4

[5] M. Frigon, A. Granas, Résultats de type Leray-Schauder pour des contractions sur des espaces de Frchet, Ann. Sci. Math. Qubec, 22 (1998), 161-168. 4

[6] W. A. Kirk, N. Shahzad, Remarks on metrics transform and fixed point theorems, Fixed Point Theory Appl., 2013 (2013), 11 pages. 4

[7] V. L. Lazăr, Fixed point theory for multivalued ф-contractions, Fixed Point Theory Appl., 2011 (2011), 12 pages. 3.13

[8] T. Lazăr, D. O'Regan, A. Petruşel, Fixed points and homotopy results for Ćirić-type multivalued operators on a set with two metrics, Bull. Korean Math. Soc., 45 (2008), 67-73. 4

[9] T.-C. Lim, On fixed point stability for se-valued contractive mappings with applications to generalized differential equations, J. Math. Anal. Appl., 110 (1985), 436-441. 3

[10] J. T. Markin, Stability of solution sets for generalized differential equations, J. Math. Anal. Appl., 46 (1974), 289-291. 3

[11] G. Moț, A. Petruşel, G. Petruşel, Topics in Nonlinear Analysis and Applications to Mathematical Economics, Casa Cărţii de Ştiinţă, Cluj-Napoca, (2007). 2, 3.7

[12] H. K. Pathak, N. Shahzad, A new fixed point result and its application to existence theorem for nonconvex Hammerstein type integral inclusions, Electron. J. Qual. Theory Differ. Equ., 2012 (2012), 13 pages. 1

[13] H. K. Pathak, N. Shahzad, A generalization of Nadler's fixed point theorem and its application to nonconvez integral inclusions, Topol. Methods Nonlinear Anal., 41 (2013), 207-227. 1.1, 1, 1.2, 1, 2.1, 2.2, 2.3, 2.4

[14] A. Petruşel, Multivalued weakly Picard operators and applications, Sci. Math. Jpn., 59 (2004), 169-202. 2.9, 2.10, 2.11, $2.12,3.5,3.6$

[15] A. Petruşel, I. A. Rus, The theory of a metric fixed point theorem for multivalued operators, Yokohama Publ., Yokohama, (2010). 3

[16] I. A. Rus, Generalized Contraction and Applications, Cluj Univ. Press, Cluj-Napoca, (2001). 3.8

[17] I. A. Rus, M.-A. Şerban, Some generalizations of a Cauchy lemma and applications, Presa Univ. Clujeană, Cluj-Napoca, (2008). 3.10 